\title{
ONLINE ENCOUNTERS: A NEW METHOD OF CREATING PARTICIPATORY ART
}

Rebecca Gamble

MA Interactive Art and Design

University College Falmouth

14 Warwick House

1 Wells Road

Malvern

Worcestershire

UK

rebecca.gamble@yahoo.com

www.rebeccagamble.co.uk

\begin{abstract}
The emergence of Web 2.0 technologies has moved our social activities online, and revolutionised the way we meet people and how we communicate with each other on a day-to-day basis. In turn, this has developed new platforms for artists to create and present work in, to network with other practitioners, and for participatory work to flourish, with opportunity for worldwide collaborations. Online social networking has become part of our $21^{\text {st }}$ Century culture, and is increasingly being incorporated into artworks, as a platform for collaboration; as a virtual space to encounter new art forms, new people and new networks; and to develop online communities.
\end{abstract}

\section{INTRODUCTION}

Claire Bishop (2006) describes how, within participatory work, social activities such as dancing samba, drinking beer and running a café have been appropriated by artists in their attempts to collapse the distinction between performer and audience, professional and amateur, production and reception. [1]

More and more these social activities are moving to online spaces, and now, artists who create interactive work have new platforms in which to invite participation, and many accessible and open-source softwares to use to network within. The chance elements that exist within these virtual environments, of encountering new audiences and new perspectives, are embraced, as the distance commonly found between artist and audience is closed, and instead replaced by a platform for collaboration.

In September 2007 I created Chat Box, [see Figure 1 and 2] a communication booth that was networked online for a 6-day event, using the communication method of Skype. A social network of friends, artists and strangers, were invited through various networking sites, to interact online by calling or texting Chat Box using Skype.

Similarly to relational work of the 1990s, this work operated within the practical and theoretical sphere of inter-human relationships; bringing into play modes of social exchange, interaction with the viewer, and processes of today's accessible communication methods, used to bring together individuals. [2] 
Participatory art relies on audience interaction and group collaboration, often celebrating a collective dimension of social experience, and developing communities of those involved.

This paper aims to map the history and development of socially engaged participatory art by discussing the outcomes from my action research methodology; investigating how online encounters have become a new method of creating participatory art, by presenting selected texts from a variety of sources, and in a handful of brief case studies of significant artworks. The paper will include:

- The historical context

- The conceptual framework

- Communication spaces

- Art as social experience

- Networks and Encounters as media

\section{In context}

The historical context of participatory work is held in the Conceptual Art movement of the 1950s and 1960s, specifically of Fluxus events and performances, the Situationists 'constructed situations' and Allan Kaprow's 'Happenings'.

In its free and easy approach, Fluxus meant to create a relationship between art and life. Everyday things, gestures, encounters, and the simplest of actions like breathing or smoking became Fluxus works. This type of work celebrated everything as art, it pointed without judging to our most repeated actions, our most travelled journeys, our most inhabited spaces, that made up, literally, the day to day, therefore making the work accessible to a wider audience. [3]

The Situationist co creator and artist Guy Debord outlined his theory of 'constructed situations' as participatory events, which remain an important point of reference for artists working with live encounters, where the audience becomes the active participant: [4]

"The Situationist International offered a collective vision of performance as social intervention, in its continuation of the surrealist dream of overcoming the distinctions between art, politics and everyday life through critically 'constructed situations', which modified the urban environment in subversive ways... abolishing the division between performance and observation." [5]

Similarly abolishing the division between performance and observation, Allan Kaprow's Happenings were structured events:

"While they may involve large areas of space, the format of the Happening is kept relatively simple, with the emphasis on establishing a participatory aesthetic." [6]

\section{Conceptual framework}

Nicolas Bourriaud, French curator and author of Relational Aesthetics, uses the term 'relational art' to describe the artistic practices of meetings, encounters, events, games 
and various types of collaboration which celebrate human relations and their social context. [7]

In his writings he highlights the importance of this type of artwork, and ultimately how to understand it and how to approach it critically. He explains how we can no longer regard contemporary works as a space we have to walk through. Contemporary art resembles a period of time that has to be experienced, or the opening of a dialogue that never ends. [8]

I am particularly interested in his perceptive on a work functioning as a relational device with a degree of randomness; it can be a machine for provoking and managing individual or collective encounters. [9]

The incorporation of common and accessible technological tools, within artworks can be a successful method to invite audience participation, due to its recognisable and therefore approachable nature.

The structure of Chat Box resembled a public telephone box; a lit CHATBOX sign was situated above the entrance, and was written in the same font as TELEPHONE, with the intention to offer an immediate understanding of the works purpose; a functioning communication booth.

By utilising everyday spaces and using common technologies participants may already be familiar with, the audience are more likely to relax and participate, and instead, importance is drawn to conversation and the common understandings experienced in these social spaces.

\section{Communication spaces}

The environment and situation in which the participatory work takes place is an important consideration for each individual work or event. Explorations of everyday environments, interventions in social scenarios, and encounters with strangers become artworks through the carefully documented accounts of these performative interactions.

Anthony Howell explains how: "Interactive performance may require specific locales, it may be crucial to the effect of the work that the performance takes place in a real space. For if the performance deals with the reality of actions rather than their mere representation, then naturally it must deal with the reality of the spaces in which those actions occur." [10]

French artist Sophie Calle's work thrives on meetings with strangers, she performs in a subtle and playful way, embracing various jobs, such as chamber maiding, and following instructions from others, as methods to approach her interventions in spaces. Phonebooth 1998, followed instructions to immerse herself in a particular environment of everyday life, to act out the role of a fictive character and play a game, written by collaborator Paul Auster. [11] These instructions included smiling, talking to strangers, and cultivating a spot. For this she chose a public phonebooth in New York. During this performance Calle ritualistically cleaned and re-decorated the phonebooth with flowers, cigarettes, orange juice, paper, pens, newspapers, magazines and a seat. The encounters with strangers were documented through a photographic diary.

Another example of a participative event which appropriated an existing telecommunication as the platform for interaction is Dialtones: A Telesymphony, created 
by Golan Levin, and collaborators; Scott Gibbons, Gregory Shakar, and Yasmin Sohrawardy.

"'Dialtones' is a performance artwork, which redirects our attention to the unexplored musical potential of a ubiquitous modern appliance, and inverts our understandings of private sound, public space, electromagnetic etiquette, and the fabric of the communications network, which connects us." [12]

The audience and their personal mobile phones became the collaborative network for this sound piece of ring tones and alerts, using a theatre space; the seated audience were amongst the symphony of sounds usually understood as unacceptable in these environments. On stage a live diagram represented the performing phones in the space as they were sounded, exposing the networks of the participants and the elements of communication distribution.

Web 2.0 technologies are a group of technologies that have become deeply associated with the terms: blogs, wikis, and podcasts, which facilitate a more socially connected Web space where everyone is able to add to and edit the information space. [13] This offers opportunities for collaboration in virtual environments, new technological tools to use to create artworks and events, and new networks to invite audiences and participation.

\section{Art as social experience}

These collaborative environments "open dialogue around issues within given contexts, within and between communities. Participants are engaged in a manner, which facilitates productive self-expression, increases social awareness, and challenges cultural roles. In ethical art practice the perspective of each individual participant is actively solicited, and incorporated without censorship." [14]

Chat Box aimed to act as a platform for open discussion and interaction, to offer a space for collective experiences, where participants could feel part of a community.

The audience were invited to participate in whichever way they felt comfortable, suggestions were offered; to make or answer a call; add to the group text-chat online; have a conversation with a stranger; invite friends to the network; write a message; place a request to rent the space for a future event; or simply experience the space. [15] Each invitation was individually printed on a business card and presented inside the booth, available to be taken away; appropriating the type of distribution of information found in public phone boxes; advertising taxis numbers and dating lines.

A series of social events were scheduled and performed using Chat Box: an online drinks party coincided with the private view, where participants were invited to bring a drink of their choice to celebrate the opening of the exhibition. A more private event of an online date occurred between two participants, one inside the booth in the UK gallery, the other at their home in Mexico, connected through conversation using the communication method of Skype.

Artist Rirkrit Tiravanija is an artist concerned with the functionality of spaces, he creates interactive, performative installations in the gallery space that challenge the conditions, expectations and role of this public space by blurring its boundaries with 
private activities, such as cooking, eating, drinking, socialising and sleeping. He uses these everyday social scenarios and associations as a tool to open a dialogue between the art, the art gallery and its audience, and make the experience a much more personal and intimate occurrence.

There is an unpredictable element of live events as artworks, in which the artist needs to consider the possibility that the work will not go to plan, or the participant's response may be a negative one. The openness of the work to this chance occurrence is vital, as a hierarchy of artist or moderator over participant defeats the collaborative nature of the work.

Networks and encounters as media

Projects Unedited is and is an excellent example of a virtual community, at the heart of a-n's new website Artists Talking, which offers a platform for collaboration, enabling artists to network internationally.

Jane Watt, author of The Art of Blogging explains the possibilities of Projects Unedited, as: a growing collection of unedited writings by artists; a virtual space where artists can find support and peer-led advice and discussion; an accessible medium for expression; a discipline for reflection; a public platform for dissemination; a resource for real-life projects, artist process and practice. [16]

The concept of social networks, specifically dialogue and connections between people and places, with the hope of bringing art closer to the everyday, is an influence for participatory art. Hannah Firth, author of Art For Networks, describes networking as 'something we take for granted, or may even be unaware of; from chatting at a gallery opening, to scribbling down email addresses on the back of a beer mat'. [17] The elements of sociability, participation and community at the heart of this concept motivate works that celebrate forms of networking.

Participants are engaged in a manner, which facilitates productive self-expression, increases social or political awareness, and challenges cultural codes. In ethical art practice the perspective of each individual audience/participant is actively solicited, and incorporated without censorship. [18]

\section{CONCLUSION: ONLINE ENCOUNTERS; A NEW METHOD OF CREATING PARTICIPATORY ART}

Web 2.0 has had such a huge impact on the way we communicate, network and create work, 'collaboration, contribution and community are the order of the day and there is a sense in which some think that a new 'social fabric' is being constructed before our eyes.' [19]

Throughout an action research methodology and Events for a Conversation; a series of social events and interventions performed in physical and virtual spaces, in which participants were invited to interact, communicate with, and respond to their surroundings, I have experienced online encounters as creative tools for developing participatory artworks.

The outcomes of these events, informed Chat Box, including ideas of how to invite participation, how to start a conversation, and how to make the audience feel comfortable 
in situations. The previous online event 'fancy a skype chat', [figure 3] for example, found the task of moderator difficult and demanding, and the constant reminder of who was in control meant there could be no collapse in the distinction between artist and participant. The Skype identity of Chat Box is 'Chat Box' not 'Rebecca Gamble', and therefore gave a neutral identity, with no one-moderator. The option to not have the web camera on during conversations gave participants more confidence to chat freely. And finally the decision to let the audience document the events through photographs and comments made the finished blog a collaborative success for the community of participants involved.

At EVA London 2008 I will be holding a participatory workshop, to explore new ideas and develop new spaces for interaction and participation, and to expose and discuss the networks of successful online projects.

\section{FIGURES}


EVA 2008 London Conference 22-24 July

Rebecca Gamble

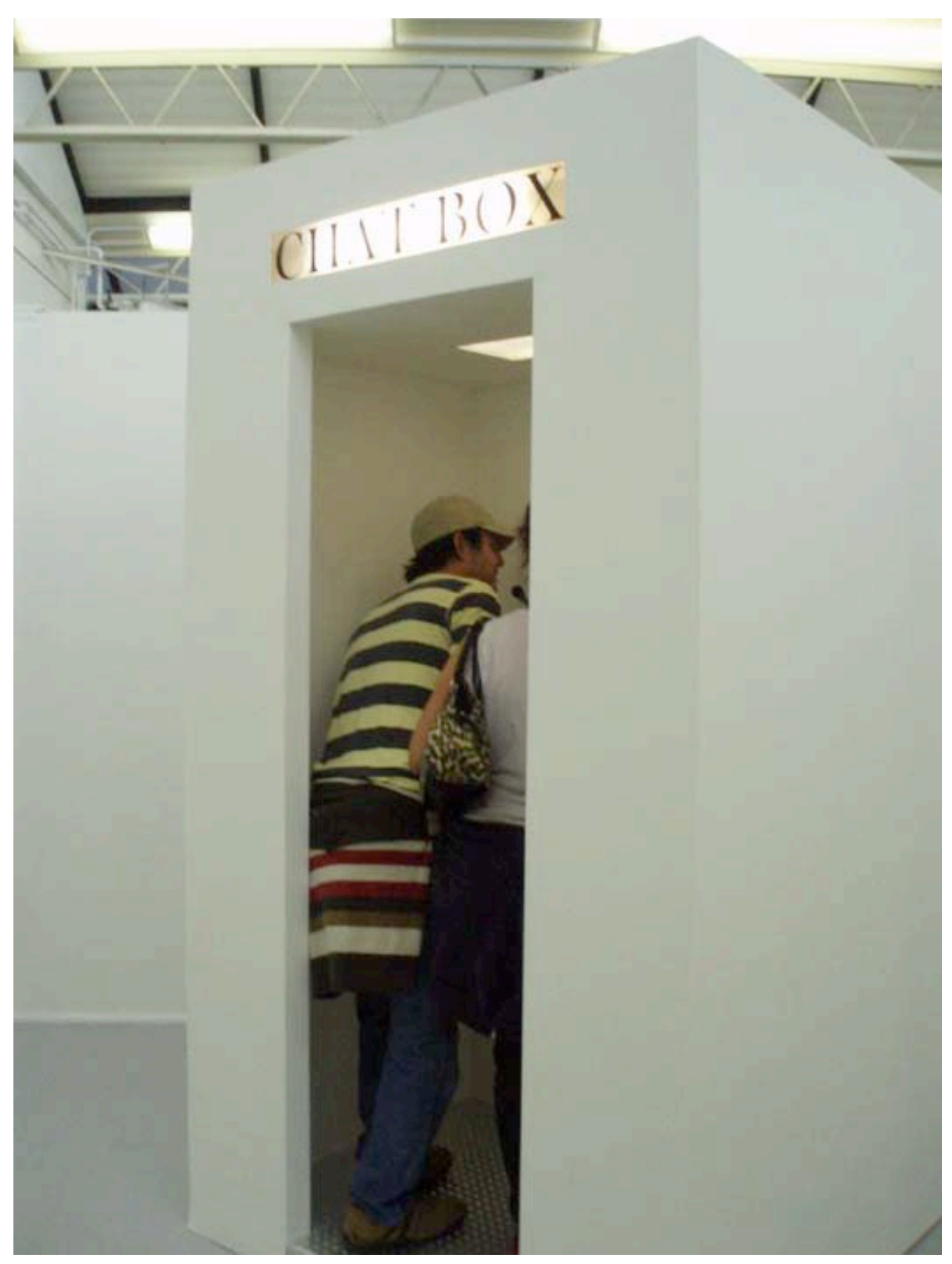

Figure 1. Chat Box: Rebecca Gamble: September 2007 
EVA 2008 London Conference 22-24 July

Rebecca Gamble

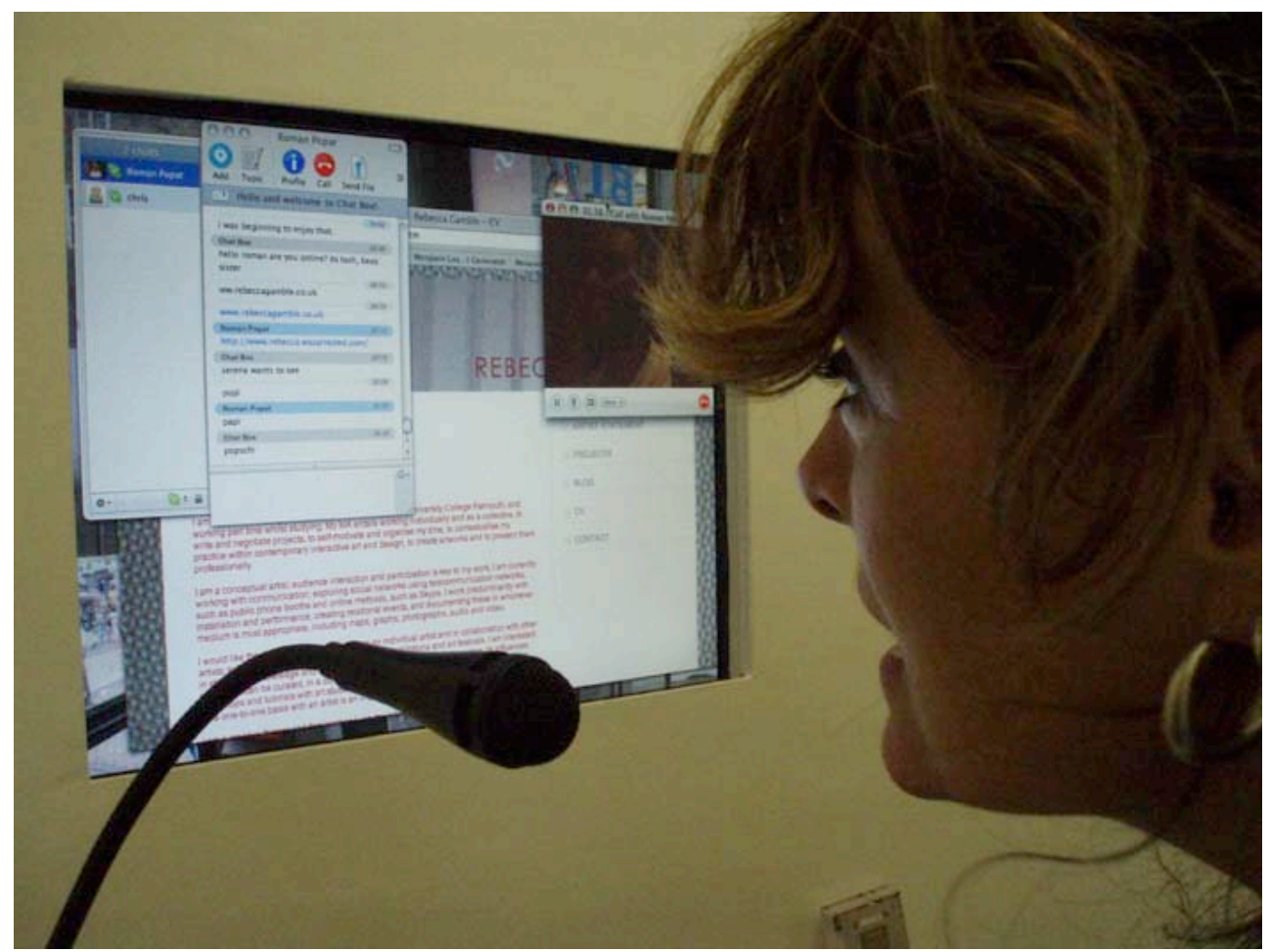

Figure 2. Chat Box: Rebecca Gamble: September 2007

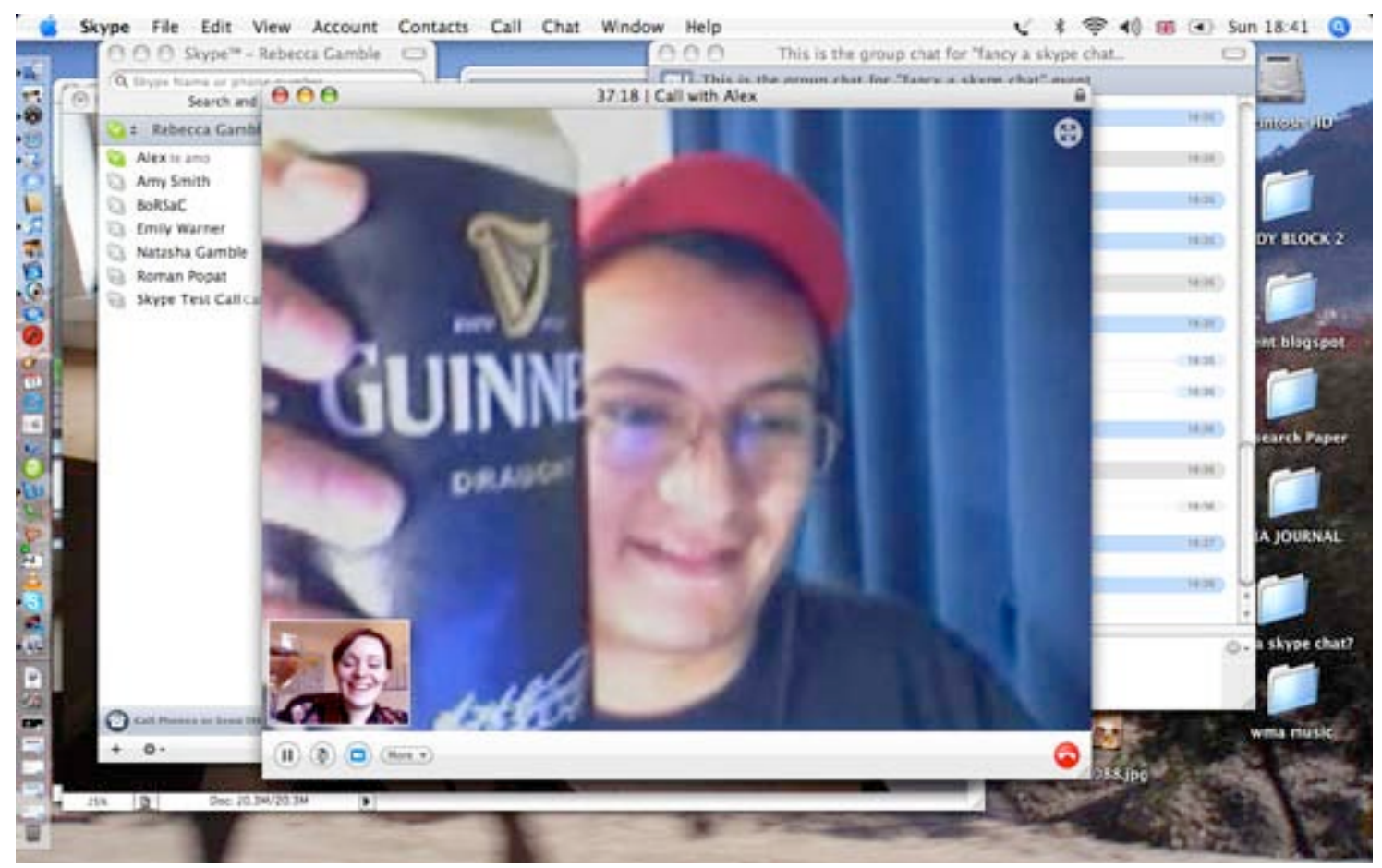

Figure 3: Fancy a skype chat? Rebecca Gamble, March 2007 
EVA 2008 London Conference 22-24 July

Rebecca Gamble

References

[1] BISHOP, C: Participation, pp. 10, 2006

a. BOURRIAUD, N: Relational Aesthetics, pp. 43, 2002

- $\quad$ HIGHMORE, B: Everyday Life and Cultural Theory: An Introduction, pp. 12, 2002.

[2] BISHOP, C: Participation, pp. 96, 2006

- $\quad$ OSBORNE, P: Conceptual Art; Instruction, Performance Documentation, pp. 20, 2002

[3] OSBORNE, P: Conceptual Art; Appropriation, Invention, Everyday; Guy Debord's definitions, pp. 217, 2002

[4] BOURRIAUD, N: Relational Aesthetics, pp. 113, 2002

[5] BOURRIAUD, N: Relational Aesthetics, pp. 15, 2002

[6] BISHOP, C: Participation, pp. 163, 2006

[7] HOWELL A: The Analysis of Performance Art, A guide to its Theory and Practice, pp. 177, 1999

[8] CALLE, S: Double Game and the Gotham Handbook, pp. 274, 1994/2000

[9] www.flong.com/telesymphony/

[10] ANDERSON, P: What is Web 2.0? Ideas, technologies and implications for education, pp. 5, 2007

[11] DANIEL, S: Collaborative Systems: Redefining Public Art; Art as Social Function, pp. 1, 2000

[12] www.rebeccagamble.co.uk/page2.htm

[13] WATT, J: a-n Collections: The Art of Blogging, pp. 7, 2008

[14] FIRTH, H: Art for Networks, pp. 4, 2002

DANIEL, S: COLLABORATIVE SYSTEMS: Redefining Public Art, pp. 1, 2002

[15] ANDERSON, P: What is Web 2.0? Ideas, technologies and implications for education, pp. 4, 2007 